\title{
The nitrogen cycle in the ocean, past
} and present

\section{$2^{\text {nd }}$ NICOPP meeting, Halifax, Canada, 8-10 June 2011}

Patrick A. Rafter ${ }^{1}$, S.L. Jaccard ${ }^{2}$, E.D. Galbraith ${ }^{3}$, T. Kiefer ${ }^{4}$ and M. Kienast ${ }^{5}$

'Department of Geosciences, Princeton University, Princeton, USA; prafter@princeton.edu

${ }^{2}$ Climate Geology, ETH Zurich, Switzerland; ${ }^{3}$ Earth \& Planetary Sciences, McGill University, Montreal, Canada; 4 PAGES International Project Office, Bern, Switzerland; ${ }^{5}$ Department of Oceanography, Dalhousie University, Halifax, Canada

D iscussions among the 21 scientists attending the NICOPP 2011 meeting confirm that this is an exciting time to be studying nitrogen (N) cycling in the past and present oceans. For example, measurements of the $\mathrm{N}$ isotopic composition $\left(\delta^{15} \mathrm{~N}\right)$ of marine nitrate and nitrite (the most widely available forms of marine $\mathrm{N}$ ) are now relatively commonplace and sedimentary reconstructions of past $\mathrm{N}$ cycling processes are becoming increasingly sophisticated through the use of microfossil-bound and compound-specific $\delta^{15} \mathrm{~N}$. These new techniques allow us to identify isotopic distinctions between sedimentary and species size fractions, which promise to provide an even more detailed look at past $\mathrm{N}$ cycling and related ocean conditions. Furthermore, the laboratory-based data provide crucial benchmarks for computer-based simulations of the marine $\mathrm{N}$ cycle. All of these approaches provide insight to ocean productivity and the biogeochemical processes associated with both $\mathrm{N}$ and carbon cycling, such as nitrate assimilation by phytoplankton and denitrification in oxygen-deficient zones.

Past N cycling was a dominant topic for two themes of the meeting: the global sediment $\delta^{15} \mathrm{~N}$ database (proposed at NICOPP 2010, Galbraith et al. 2010) and the impact of diagenesis on whole sediment $\delta^{15} \mathrm{~N}$ (total combustible sedimentary N; also known as "bulk").

\section{Global sediment $\delta^{15} \mathrm{~N}$ database}

To date, 138 records of whole sediment $\delta^{15} \mathrm{~N}$ variability covering the last ca. 2.5 Ma have been compiled into a database, which will be described in a publication and made available to the community shortly (Fig. 1). The compilation is promising but also highlights the need for enhanced geographical coverage in particular in the largely neglected subtropical gyres and most of the Southern Hemisphere. This sediment $\delta^{15} \mathrm{~N}$ database will be a powerful tool for reconciling marine $\mathrm{N}$ cycling with past changes in the mean climate state.

\section{The influence of diagenesis}

Even with significant developments in the use of alternate sedimentological $\delta^{15} \mathrm{~N}$ records such as microfossil-bound and compound-specific $\delta^{15} \mathrm{~N}$, much of our knowledge of past $\mathrm{N}$ cycling processes will continue to rely on whole sediment $\delta^{15} \mathrm{~N}$, given that it can be measured in any sediment at relatively

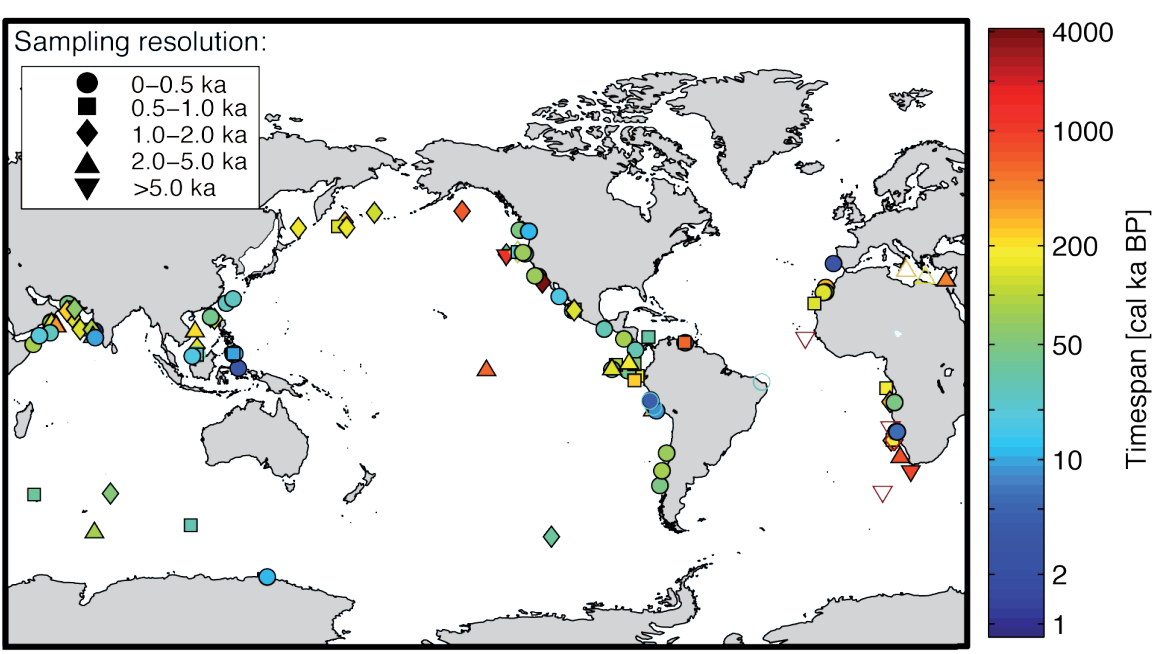

Figure 1: Global distribution of available sedimentary $\delta^{15} \mathrm{~N}$ records, together with their respective temporal coverage and resolution. Cores that do not cover the last glacial cycle are marked by an open symbol. low cost. However, at some sites, coretop whole sediment $\delta^{15} \mathrm{~N}$ is elevated relative to the expected export from the modern surface ocean. The underlying cause of the $\delta^{15} \mathrm{~N}$ enrichment is assumed to be the preferential loss of ${ }^{14} \mathrm{~N}$ during the remineralization of freshly deposited organic matter or "diagenetic fractionation".

This issue was a major concern of NICOPP 2011 with several presentations dedicated to using the global sediment $\delta{ }^{15} \mathrm{~N}$ database and whole sediment / microfossil $\delta^{15} \mathrm{~N}$ measurements to discuss why and where diagenetic fractionation is important. Among these discussions, several investigators independently converged on the finding that coretop whole sediment $\delta{ }^{15} \mathrm{~N}$ in the deep-sea, which ranges from $1-17 \%$, is on average $2 \pm 2 \%$ higher than values from sediment trap time series at the same sites. However, where coretop sediments were measured for both whole sediment and microfossilbound $\delta^{15} \mathrm{~N}$ (assumed to be resistant to diagenetic alteration) they generally agreed. These findings suggest that coincident measurements of whole sediment and microfossil-bound / compound-specific $\delta{ }^{15} \mathrm{~N}$ will help answer why deep-sea coretop sediment $\delta^{15} \mathrm{~N}$ is elevated, by illuminating the molecular transformation of sedimentary organic matter. Furthermore, where the fidelity of whole sediment $\delta^{15} \mathrm{~N}$ is assured (i.e. in the case of little terrigenous input and minimal diagenetic fractionation) differences with microfossil-bound $\delta^{15} \mathrm{~N}$ could provide new insight to surface ocean $\mathrm{N}$ cycling processes.

\section{Interlaboratory calibration}

On a different note, a laboratory intercalibration was proposed to optimize comparison between whole sediment $\delta{ }^{15} \mathrm{~N}$ records. Laboratories interested in joining the effort should please contact Mark Altabet (maltabet@umassd.edu).

\section{Reference}

Galbraith E, Kienast M and Kiefer T (2010) PAGES news 18(2): $92-93$ 